\title{
Exploring L2 learners' Task-related Identities in a Reading Circle Task Through Conversation Analysis
}

\author{
Hoa T. V. Le \\ University of Hawai' $i$ at Mānoa
}

\begin{abstract}
Using conversation analysis as the research approach, this study explores how L2 learners utilize their task-related identities during task interactions and how those identities are used as resources for task management. Eight students in an ESL academic reading class formed two groups while they did their reading circle task for six rounds. In each round, the students took turns to be in charge of a specific role in the discussion session (i.e., discussion leader, notetaker, vocabulary definer, and contextualizer). Data was collected from all rounds and analyzed for emerging patterns. Results showed that (a) the participants used each other's assigned identities skillfully to orient the group to the institutional goal, and (b) the participants used their own existing obligations to problematize the task interactions. By providing insights on those dynamic task-related identities, this study broadens our understanding of interactions happening at the task implementation stage and suggests pedagogical implications.
\end{abstract}

\section{Résumé}

S'inscrivant dans le courant de l'analyse de la conversation, cette étude explore comment les apprenants d'anglais utilisent leurs identités liées aux tâches lors des interactions entre les tâches et comment ces identités sont utilisées comme ressources pour la gestion des tâches. Huit étudiants dans une classe de lecture universitaire en anglais ont formé deux groupes pendant qu'ils effectuaient leur tâche de cercle de lecture pendant six tours. À chaque tour, les étudiants se sont relayés pour être responsables d'un rôle spécifique dans la session de discussion. Les données ont été collectées à tous les cycles et analysées afin de dégager les éléments les plus saillants. Les résultats ont montré que (a) les participants utilisaient habilement les identités qui leur avaient été attribuées pour orienter le groupe vers l'objectif identifié en amont; et que (b) les participants ont utilisé leurs propres obligations existantes pour problématiser les interactions entre les tâches. 


\section{Exploring L2 Learners' Task-related Identities in a Reading Circle Task through Conversation Analysis}

Creating an environment where meaningful interactions happen for second language learners is one of the most important goals of task-based language teaching (Ellis, 2003; Long, 2015; Skehan, 1998). Tasks that require pair or group work, where learners share common goals and interact with each other in a meaningful way, are desirable because they are believed to lead to more negotiations among participants, which benefits interlanguage development (Long, 2015). However, in order for learning to happen, many factors should be taken into consideration, one of which is the match or mismatch between task design and implementation. Breen (1987/2009) argued that a task is designed with a 'blueprint,' but also has a fluidity, so it often departs from the original plan of the task creator (i.e., the teachers) when it was carried out by the learners. In other words, task design is not a guarantee for a maximization of learning opportunities for language learners as often hoped for by the task designers. In Breen's words, learner outcomes are "often diverse, sometimes unexpected, and occasionally downright disappointing" (1987/2009, p. 334). Therefore, in order to evaluate the effectiveness of a task, close examination of the execution of a task is important. In light of that, many researchers have called for more research that analyzes the details of the task-in-process and interactions of learners as they do the task (e.g., Ellis, 2005; Samuda, 2015).

In response to such calls, there has been a growing body of research examining tasks in process (e.g., Balaman \& Sert, 2017a, 2017b; Hauser, 2009, 2013; Hellerman \& Cole, 2009; Jenk, 2007, 2009; Kasper, 2004, Markee \& Kunitz, 2013; Mori, 200; Ro, 2018). Conversation analysis (CA) is the common framework that was used in those studies. As researchers pointed out, the emic nature of CA helps researchers to examine the task participants' talks and interactions as they are displayed during the moments that the tasks are being carried out, rather than relying on the prior decisions about what is relevant and what is not (e.g., Gardner, 2019; Huth, 2011; Markee, 2000; Seedhouse, 2005). Detailed analysis of task interaction through a CA lens helps unfold the task-in-process, the resources participants use, and how they contribute to the outcome of the task. However, among the body of research on task interaction using CA approach, no studies have investigated the role of learners' task-related identities and their relationships with the learners' orientation to tasks and task interactions. There is also no research to date that examines the task-in-process during a reading circle task. Therefore, through CA, this research aims to start to fill in these gaps by investigating the process and to see how the participants used their assigned identities as resources for task interactions and to display an orientation to the institutional goals. 


\section{Background}

\section{Reading Circle and Rask}

The reading circle in ESL/EFL teaching has its origins in the literature circle initiative (Daniels, 2002), which has been used widely in teaching L1 reading. The idea behind Daniels' literature circle model is to promote joyful and collaborative learning through small, peer-led reading discussion groups whose members choose to read the same text independently but keep notes as they read. During the post-reading discussion, the learners share their ideas and interpretations of the text with the aim of comprehending the text at a deeper level. When this idea is adapted to the teaching of ESL or EFL reading, several elements of the literature circle have been changed to better fit these different learner populations (Shelton-Strong, 2011). For example, Furr (2004) suggested assigning each member of the group-specific roles such as group discussion leader, summarizer, connector, word master, passage person, and collector. The purpose was to provide L2 students with the necessary scaffolding and aid to help them fully understand the text. When it comes to teaching English for academic purposes, Seburn (2015) proposed a model called, academic reading circle (ARC) in which learners read non-fiction texts such as journal articles, reports, magazine articles, etc. rather than only typical literature like in the traditional literature circles. The roles of the circle members are also adjusted to include a leader, a connector, a highlighter, a contextualizer and a visualizer. In general, each member has a specific responsibility assigned by their roles as they read the text.

In the present study, reading circles have been adapted by the teacher to reflect 'target tasks' (Long, 1985, 2015), which the participants do in the real world (i.e., leading and participating in a group discussion) as they are all undergraduate and graduate students. In line with Shelton-Strong's (2011) argument for the alignment of reading circles with TBLT principles, the reading circle in the present study is considered a task as it incorporates Ellis' (2009) definition of tasks and the interactive framework. The discussion phase of the task is an opinion gap type since the learners use their own linguistic and non-linguistic resources to convey their opinions and primarily focus on meaning-making while doing so. The divergent outcome of the discussion or their arguments or opinions are recorded by a note-taker who is also a member of the group. The notes are shared simultaneously with other members through Google Docs and later shared with teachers as the students complete the task. The current analysis focuses on this discussion process, which is the interactive mode where the learners' assigned identities intervene in their task orientation and process.

\section{Task Interaction, Task-related Identity, and Task Orientation}

One of the important factors for examining "task-as-process" is the interaction among the participants during the task execution process. Seedhouse (1999) coined the term 'task-based interaction' to highlight the crucial role of the actual interactions that are constructed by students as they carry out the task. He also argues that the organization of the interaction varies depending on the context and "the L2 classroom has its own interactional organization which transforms the pedagogical focus (task-as-workplan) into interaction (task-in-process)" (Seedhouse, 2009, p.2). This reflexive relationship between 
pedagogy and interaction, however, contributes to the uniqueness of the interaction in the context of tasks and classroom interaction.

Task interaction is a type of institutional interaction (Arminen, 2005; Heritage \& Claymen, 2010) where learners frequently have mutual goals to achieve, and the task interaction is often locally adjusted to fit the institutional context. Seedhouse $(1996,2004$, 2009) proposed three "interactional properties" that constitute the uniqueness of goals of the L2 classroom interaction which are "(1) language is both the vehicle and object of instruction; (2) the linguistic forms and patterns of interaction which the learners produce in the L 2 will inevitably be linked in some way to the pedagogical purposes which the teacher introduces; and (3) the linguistic forms and patterns of interaction which the learners produce are subject to evaluation by the teacher in some way" (Seedhouse, 1996, p.109). While these three interactional properties follow in consecutive sequences from each other, the specific goal orientations are tied to the learners' "institutional-relevant identities" (Heritage \& Claymen, 2010, p. 34). Those identities, also known as discourseinternal identities (Kasper, 2004), are associated with the participants' assigned responsibilities for a specific task and only occur during the task implementation, but frequently contribute to the nature of the participants' interactions.

The identity-based goals, as well as special constraints that are particular to the specific contexts of the tasks, usually distinguish this type of institutional talk from other mundane conversations. Those differences display in areas including the turn-taking organization, overall structural organization of the interaction, as well as sequence organization and turn design (Drew \& Heritage, 1992).

Research that studies students' task-based interaction through the lens of CA has been quite diverse, both in terms of the task types and the focus of the analysis. For example, Mori (2002) and Kasper (2004) both examined the pair work between an L2 language learner and a native speaker. In Mori's (2002) study, the analysis focused on how the turn-taking organization of the talk-in-action was shifted from a discussion model as in the 'task-as-workplan' into the question-answer model like in an interview which happened in the 'task-in-process'. Kasper's (2004) analysis however focused on the situated identities, social membership categories, and interaction-internal statuses of the learners in the dyads. Among studies that examine group discussion tasks, Hauser (2009) identified patterns of turn-taking and primary speakership negotiations as learners discuss teacherassigned questions based on a scenario presented in a textbook. Hellermann and Pekarek Doehler (2010) analyzed the interactions of three groups of L2 students who were doing similar teacher-designed tasks and explored how the learners approached the task in different trajectories in each group despite the similarity of the tasks themselves.

One of the few studies that directly explored learners' task orientation during task interaction is Hauser's (2013) study of Japanese students in an ESL class. In this study, he explored how the learners display their orientations to the task class as they pursued their intersubjectivity or the "shared understanding of what the participants are saying and doing in the interaction" (p. 287) and going beyond that. The institutional goal in the context of his study was for learners to use English as they participate in their interactions, which Seedhouse called the first "international property" since the English language is both the vehicle and object of instruction. To achieve intersubjectivity, the learners use their L1 during the task. However, after the intersubjectivity is achieved, Hauser found out that the 
learners often go beyond that and translate the Japanese words that they use into English which is the institutionality.

The current study hopes to contribute to this territory of research in task interaction by investigating how learners refer to their assigned identities as interactional resources as well as using those identities as strategies to display their orientation to the institutional goals. Their context-specific responsibilities can also be problematized when there are issues arising during the task execution.

\section{Turn Taking Organization and Primary Speakership in Group Work}

When examining the task interaction under CA scope, it is important to look at the organization of turn taking because as Seedhouse (2005) pointed out, this organization is often constrained and related closely to the institutional goal. Previous literature has analyzed contexts when the organization of turn taking that occurs in task interaction resembles or deviates from the mundane conversation. Sacks et al. $(1974,1978)$ used turnconstructional units (TCUs) and transition relevance place (TRP) as elements that constitute the organization of turn taking in mundane conversation. At a TRP, a speaker has come to a point of possible completion and the turn allocation can have multiple trajectories such as (a) to the next speaker who is nominated by the previous speaker, (b) to a speaker who self-selects or (c) the current speaker can continue. While these rules stay constant and context-free in mundane conversations, in institutional settings, the participants often "employ these context-free organizations in a context-sensitive way to display their social actions" (Seedhouse, 2005, p.168). Hauser (2009) also noted, "the way in which participants organize their turn-taking often displays an orientation, or lack of orientation, to the institutional setting" (p.216). In other words, how the local context, or in this case the context of the task will determine how a participant constructs their talk interactions.

One important feature of the turn-taking system for group discussion, which is different from ordinary conversation, is the notion of primary speakership. In group interaction, one student participant can remain in the role of primary speaker for an extended period of time, while other participants usually respond in minimal turns (Hauser, 2009). According to Hauser, the transition from the role of primary speaker and the negotiation for that to happen is also context-sensitive, locally adjusted, and co-constructed by the participants during the task interaction. The current study also uses these notions of primary speakership and the negotiation of shifting roles to answer the following research questions:

RQ1. How do the participants use their task-related identities in interactions? RQ2. How are those identities used as resources for task management? 


\section{Data and Methodology}

\section{Context}

The research was conducted in an English as a second language (ESL) academic reading classroom in a language program at a state university in America. The class was an advanced academic reading class, which is the highest-level reading skill for this program. It was designed in a hybrid mode, which means the students and the instructor met once per week in a computer lab for 75 minutes. They also did the equivalence of 75 minutes of online class learning asynchronously.

All students in the class had either taken an institutional placement test to be in the class or moved up to this level after successfully passing an intermediate academic reading class in which they needed to earn at least a 75\% grade. The students in this English program were, at the time, regular undergraduate and graduate students at the university. Therefore, while taking this advanced academic reading class, they were also taking other courses in their majors.

The teacher of the course was a graduate student in her last semester in the master's degree program in applied linguistics. She was also taking a graduate course on Task-based language teaching (TBLT) at the time of this research. The researcher was not the teacher of the class.

\section{The Task}

The task is called 'reading circle,' which adapts Seburn's (2015) academic reading circles model with modifications in the roles of the participants by the teacher of the class. In this task, the students formed groups of four and worked in their group to discuss a twoto three-page academic reading or text. The goals of the task are (a) to explore a specific topic through reading different types of articles; (b) to improve vocabulary and practice reading strategies; (c) to gain experience researching and preparing a discussion on articles; and (d) to gain experience leading and participating in small group discussions based on in-class readings. Every week, in their groups, each student had a distinct role: a discussion leader, a note-taker, a contextualizer, and a luminary. Each member's role in the group is described in detail in Table 1. 
Table 1

Summary of Participant's Task-related Role and Main Responsibilities

\begin{tabular}{ll} 
Assigned identities & Responsibility description \\
\hline Discussion Leader & $\begin{array}{l}\text { Choose an article for discussion } \\
\text { Prepare three discussion questions } \\
\text { Facilitate and lead the discussion } \\
\text { Send peer evaluations to all other members }\end{array}$ \\
Notetaker & $\begin{array}{l}\text { Prepare three comprehension questions } \\
\text { Take notes during the discussion }\end{array}$ \\
& $\begin{array}{l}\text { Make sure everyone speaks in the discussion } \\
\text { Send peer evaluations to all other members }\end{array}$ \\
& $\begin{array}{l}\text { Prepare at least five important words and three grammatical } \\
\text { features from the reading }\end{array}$ \\
& $\begin{array}{l}\text { Discuss those vocabulary and grammatical features during the } \\
\text { discussion }\end{array}$ \\
& Send peer evaluations to all other members \\
& $\begin{array}{l}\text { Submits/shares at least } 3 \text { connection points that show how } \\
\text { articles' concepts connect to other areas \& what one needs to } \\
\text { know about the outside world to understand the text }\end{array}$ \\
During discussion: State connections between article \& other \\
domains, ask others connections/contextualization. \\
Send peer evaluations to all other members
\end{tabular}

Although not specifically mentioned in the documents, all participants should answer the questions or discuss the question during the circle session. The discussion leader submits and shares an article to the teacher and to their group, writes a short summary, and at least three discussion questions before the day of the Reading Circle task. During the discussion, the leader facilitates the discussion by briefly summarizing the article and moves on to choosing any of the comprehension or discussion questions to get the conversation started.

The notetaker, which is an addition to Seburn's (2015) ARC model is required to submit and share at least three comprehension questions with the group before the discussion. These questions are different from the leader's discussion questions because they check the reader's comprehension of the text (i.e., who, what, when, where, and why questions), instead of questions that invite a deeper discussion beyond the text as in the discussion questions. During the discussion, the notetaker is asked to document the group discussion. The notetaker also should make sure everyone speaks in the group with prompts like "we haven't heard from you yet," or "what do you think about x?" Finally, the notetaker checks for agreement within the group to see if everyone agrees on the same answers to the comprehension and discussion questions and continues the discussion until an agreement has been reached.

The contextualizer makes the connection points between the reading to real life or to other relevant readings or literature. Before the discussion, they post and share three 
connection points with their group members. They need to analyze how the article's concepts connect to other areas and what they need to know about the outside world to understand the text. During the discussion, their job is to state the connections between the article and other domains and ask others for additional connections and contextualization.

Lastly, the luminary, adapted from Seburn's 'highlighter' role is in charge of the vocabulary of the reading. Before the discussion, they submit and share at least five important or interesting vocabulary words and their definitions and identify three key grammatical items or phrases to the group. During the discussion, they work with the group to define the provided vocabulary and talk about how the grammatical items and phrases are relevant to the article. It is expected that all members of the group make contributions to the discussion by answering the different group members' questions. After the discussion, the members will all send the teacher their peer grading forms.

The task was used in the class for six weeks and usually took up to 20-25 minutes of class time. During the first week (Week 0), the teacher introduced the task by giving a Prezi presentation, which described the purpose of the task and how it works. The presentation was 20 minutes long. After that, the students were randomly placed into groups of four. For the purpose of this research, the participants who volunteered to participate in the research were asked to form two groups. The participants could choose which group they wanted to be in. After that, the groups did a practice round with one of the readings that they had read at home and were asked to prepare discussion questions together in their groups. The teachers went around and answered questions. By the end of the session, the teacher asked the group to decide the role of each member for the first round of the reading circle, which would happen the following week.

In the following week (Week 1), the students started doing the discussion based on the reading that the discussion leader had chosen. The students spent four weeks in their groups, making sure that everybody participated in a different role each time. After the first four rounds, the students changed their groups and did the Reading circle task for two more rounds before the class moved on to a different activity. Table 2 summarizes the flow of this task. 
Table 2

The Reading Circle Task

\begin{tabular}{|c|c|c|c|}
\hline Week & Activities & Descriptions of activities & Length \\
\hline 0 & $\begin{array}{l}\text { Task introduction } \\
\& \text { trial }\end{array}$ & $\begin{array}{l}\text { Teacher introduced the task } \\
\text { Students sit in group of } 4-5 \text { to practice } \\
\text { the task in group } \\
\text { Teacher answered students' questions } \\
\text { about the task }\end{array}$ & 40 minutes \\
\hline 1 & $\begin{array}{l}\text { Reading circle } \\
\text { task Round \#1.1 }\end{array}$ & $\begin{array}{l}\text { Students sit in their assigned group and } \\
\text { worked on Article } \# 1\end{array}$ & 25 minutes \\
\hline 2 & $\begin{array}{l}\text { Reading circle } \\
\text { task Round \#1.2 }\end{array}$ & $\begin{array}{l}\text { Students stayed in the same group and } \\
\text { worked on Article \#2 }\end{array}$ & 25 minutes \\
\hline 3 & $\begin{array}{l}\text { Reading circle } \\
\text { task Round \#1.3 }\end{array}$ & $\begin{array}{l}\text { Students stayed in the same group and } \\
\text { worked on Article \#3 }\end{array}$ & 25 minutes \\
\hline 4 & $\begin{array}{l}\text { Reading circle } \\
\text { task Round \#1.4 }\end{array}$ & $\begin{array}{l}\text { Students stayed in the same group and } \\
\text { worked on Article \#4 }\end{array}$ & 25 minutes \\
\hline 5 & $\begin{array}{l}\text { Reading circle } \\
\text { task Round \#2.1 }\end{array}$ & $\begin{array}{l}\text { Students switched to a new group and } \\
\text { worked on Article } \# 5\end{array}$ & 25 minutes \\
\hline 6 & $\begin{array}{l}\text { Reading circle } \\
\text { task Round \#2.2 }\end{array}$ & $\begin{array}{l}\text { Students stayed in the same group and } \\
\text { worked on Article \#6. }\end{array}$ & 25 minutes \\
\hline
\end{tabular}

\section{The Participants}

There were 23 students in the class and eight of them volunteered to participate in the study. Among the participants, seven were undergraduate and one participant was a $\mathrm{Ph} . \mathrm{D}$. student. The participants happened to speak different first languages. Their majors were also diverse coming from seven different departments. The majority of the participants were from 18 to 21 years old, except for Fa who was 28 years old. The backgrounds of the participants are summarized in Table 3. All the names are pseudonyms. 
Table 3

Students in the Study

\begin{tabular}{|c|c|c|c|c|}
\hline Names & First language & Age & Major & Level \\
\hline $\mathrm{Yu}$ & Japanese & 21 & Political Science & Undergrad \\
\hline $\mathrm{Fa}$ & Persian & 28 & Urban Planning & Graduate-PhD \\
\hline Chi & Chinese & 21 & $\begin{array}{l}\text { Atmospheric } \\
\text { Sciences }\end{array}$ & Undergrad \\
\hline $\mathrm{Bu}$ & Palauan & 20 & Political Science & Undergrad \\
\hline Am & Tajik & 18 & $\begin{array}{l}\text { Business } \\
\text { Administration }\end{array}$ & Undergrad \\
\hline $\mathrm{Da}$ & Korean & 18 & $\begin{array}{l}\text { Exploratory } \\
\text { Health Science }\end{array}$ & Undergrad \\
\hline Man & Thai & 20 & $\begin{array}{l}\text { Travel Industry } \\
\text { Management }\end{array}$ & Undergrad \\
\hline Lyn & French & 18 & Marine Biology & Undergrad \\
\hline
\end{tabular}

\section{The Data}

The data collection occurred during the Fall semester in 2018 with the written consent of the participants. During a class session, the researcher visited the class and announced the research plan to the class. The students understood that participation was voluntary, and they would receive a gift card as compensation; however, students would not be penalized if they chose not to participate, and they would take part in the class activities as usual. Initially, ten students expressed interest, but only eight students were recruited so that two groups of four could be formed. The participant selection process was random and based on a first-come, first-serve basis. During the six weeks of the reading circle task, the eight students were grouped together, and they were audio and video recorded. The data consists of all six times that these students did their reading circles, which makes up around three hours of video recording. Relevant portions of the recording were transcribed in detail following conversation analytic conventions by Jefferson (2004). Non-vocal conduct was transcribed using Burch's conventions (2014). Only similar patterns that emerged from those interactions are used for analysis. 


\section{Analysis}

\section{Using Task Identities for Task Orientation}

Excerpt 1. Week 5

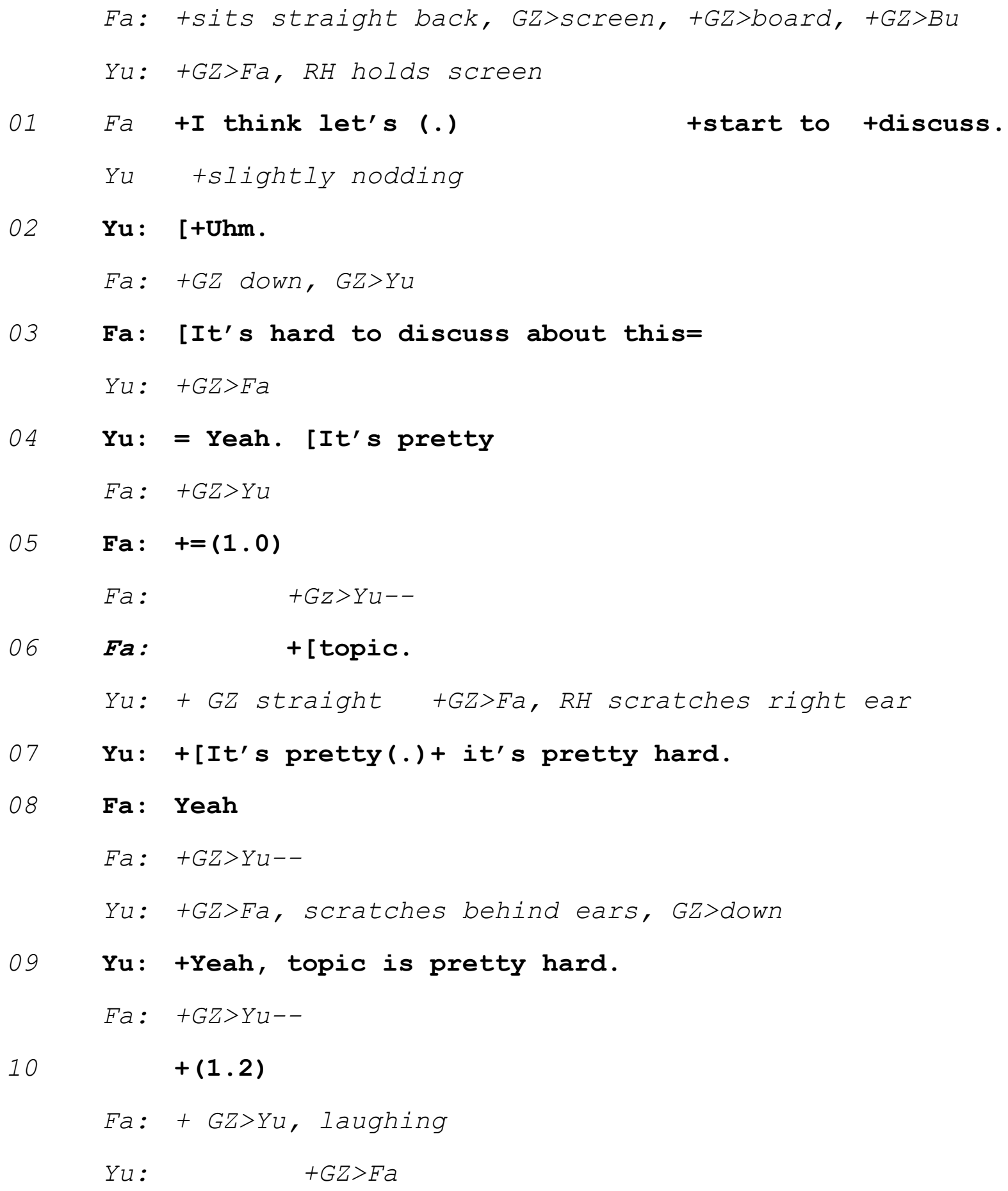


$11 \mathrm{Fa}$ : +You're tdiscussion leader so you hihih +[shouldn't say hihi that hihi.

Yu:

$12 \mathrm{Yu}$ :

Fa tlaughing

13 Fa: thihih

Yu: $\quad+$ GZ down, RH holds screen, moves it $\uparrow \downarrow$

14 Yu: +So: :=

Fa: tLeans back, GZ down, a e

$Y u: \quad+G Z>F a$ +GZ down, laughing--

15 Fa: =It shouldn't be hard +[for you hihi.

Yu :

[hahahaha.

Yu: +sits straight up, GZ>screen, $R H$ on touch pad

17 Yu: +Yeah, right.

Yu: $+B H$ pulls down t-shirt, $+G Z>F a$

18 Yu: tWell, yeah I just tchose this topic because it's kinda (.) my major.

Fa: $\quad+G Z>Y u--$

Yu: + RH at chin, GZ>screen

19 Yu: + So:: (.) Uhm::(.)

Fa: +GZ straight

Yu: $+G Z>B u$
+GZ down
$+[$ Oh yeah 
22 Fa: =Not that (we don't know), we +can't vote [so we don't have any tinformation about it.

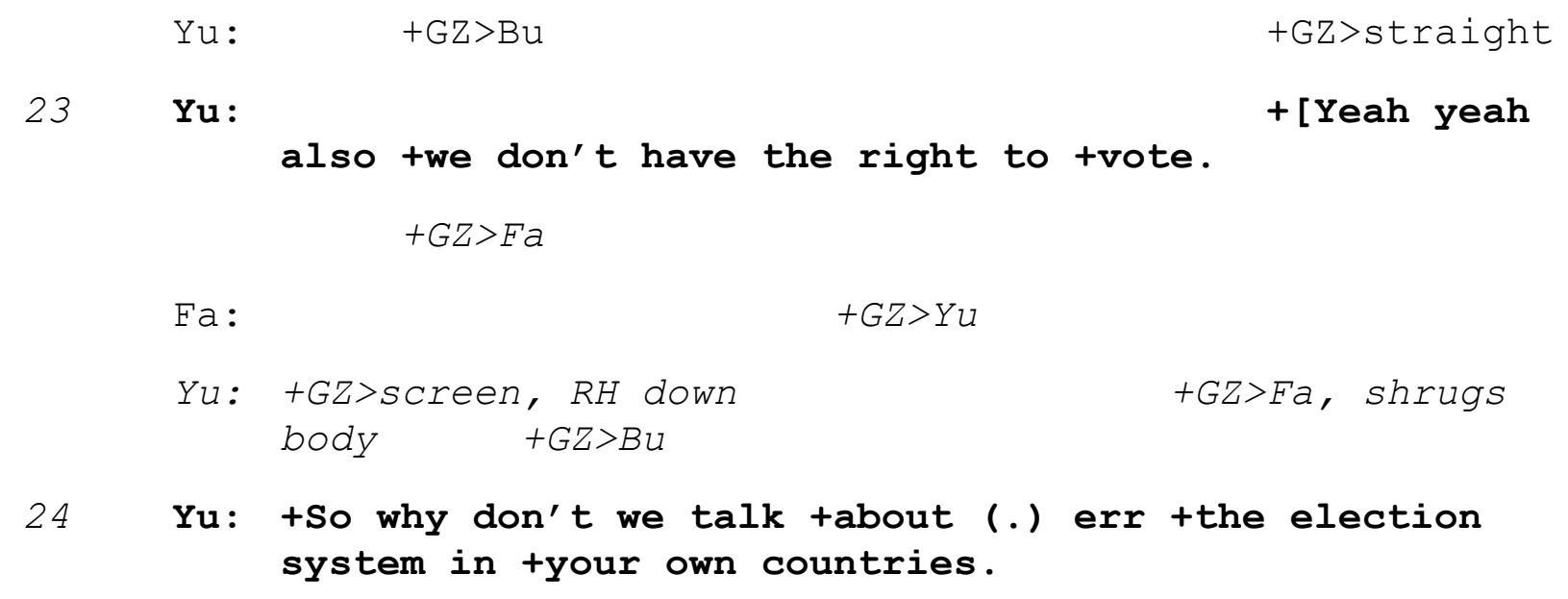

This excerpt occurred in week 5. At this point, the students had just finished four rounds of Reading Circle in one group and now joined a new group. In this week, Yu, a political science major, was the discussion leader and he chose an article about the midterm elections in the United States. The first discussion question he had for the group was "What is the main purpose of the mid-term election?" However, after the discussion session started, there was a lapse in conversation so Fa, who was the luminary, initiated the turn in Line 01. In classroom interaction (i.e., institutional interaction), pre-allocation of turn taking is a unique characteristic (Heritage \& Clayman, 2010). Therefore, as Yu was the discussion leader, he was expected to initiate the turn and lead the discussion. He also had the right to pre-allocate the turns specifically to the group members. However, he had not done it, so Fa took up the role. Fa's talk in Line 01 was again a complete unit which is a perfect TPR. At this point, Yu still did not treat it as a place for turn transition, instead, he produced a minimal response in Line 02. Right after that, Fa gave an account of why no one in the group, including herself, had answered the question in Line 03. This comment can also be seen as a complaint (Shegloff, 2000). As a consequence, Yu demonstrated that he understood what Fa said in lines 04, 07, and 09 repeatedly, which is a normal response to complaints (Shegloff, 2000, 2007). However, while repeatedly acknowledging that, Yu did not elaborate on his talk and instead there was a 1.2 second pause in Line 10.

At that point, in Line $11 \mathrm{Fa}$ used Yu's preassigned role (i.e., discussion leader) to orient $\mathrm{Yu}$ to the primary speaker's responsibility of the discussion. She challenged Yu's response and through that forced him to elaborate his opinion. Fa's laughter made her speech sound like she was teasing him, but it also played a role in her negotiation for the role of primary speaker. Yu understood Fa's challenge to him when he said "Oh yeah" before Fa completed her turn in Line 12. In Line 14, by saying "so::," it appears like Yu indexed his acceptance of primary speakership. He started moving the laptop screen back and forth, which may be a sign of feeling a bit of discomfort or simply a reaction to being put on the spot. Without a pause, Fa continued to express her account for why she thought $\mathrm{Yu}$ should not say that the topic is hard in Line 15. It was Yu who chose the article so it should not be hard for him. Again, Fa added laughter in her talk to tease Yu. At this time, 
$\mathrm{Yu}$ also laughed in response to her challenge in Line 16. His laughter came right after Fa's word "hard" and overlapped with the rest of her talk. Then, while sitting straight up, he again expressed his agreement with Fa's comment in Line 17. Then in Line 18, he gave an account for why he chose this topic. It was because he majors in political science, which was exactly the task description. By giving this account, his response was again a reasonable reaction to complaints (Shegloff, 2000, 2007). At this point, Yu showed that he was ready to take responsibility as the discussion leader. After a few hesitations in Line 19, Yu first explained why he thought the topic was difficult. The way he chose the word "we" in Line 20 makes it clear that he was talking for all the group members. This is particularly true because he said, "we don't have any background of it," which is about the American political system. As a student majoring in political science and the one who chose the article, it may not necessarily be true that Yu does not have any background of the topic, but it would be more the case regarding the other group members. At this point, Fa showed her agreement and added that because they were not eligible to vote, so they do not have any information about the election. Yu showed his approval of $\mathrm{Fa}$ 's account by repeating what she said in Line 23. But it seemed he was prepared for this since he immediately suggested the group switch to talking about the election systems in their own countries in Line 24. At this point, although the data is not shown in the excerpt, Fa was satisfied with Yu's decision to switch to a different question.

In short, by focusing on Yu's institutional identity as a discussion leader and the one who chose the article as a resource, Fa was able to show a strong orientation to the task responsibility to keep the discussion moving instead of falling into silence or lapses. She was also successful in her strategies for negotiating the primary speakership role. While $\mathrm{Fa}$ was not the discussion leader, her initiation of turns in Line 01 and her strategic uses of turns after that (lines $03,11,15$, and 22) have efficiently shaped the ongoing course of the task interaction. As one of the outcomes of this task is for participants to practice their skills to participate in an academic discussion session, this example shows an occasion where Fa used each other's roles to help move the discussion forward. In the following excerpt, another strategy is utilized by a different participant with the aim of orienting the group to their task duties. 
Excerpt 2. Week 3

Am: +GZ>screen, furrows her brow

01 Am: tLet's move on, girls?

Chi: +Pulls the laptop close to her body, Gz>screen

Am: $\quad+$ GZ>screen--

$02 \mathrm{Am}: \quad+(1.0)$

Chi: tRH touches her hair, GZ>Am, GZ>screen

03 Am: tGirls: :?

Chi: thH closes her laptop a bit, then clears things on the desk

$04 \quad \mathrm{Am}: \quad+(1.0)$

Am: $\quad+L H$ points to Chi, Gz>screen tLH at her head then to the side

Chi: $\quad+G Z>A m, G Z>$ screen $\quad+G Z>A m, G Z>$ screen

05 Am: So (.) twho would you like to talk, +notetaker or=

$06 \mathrm{Da}: \quad=[\mathrm{Oh}$

Am: tLH points to Chi, GZ> Chi tLH moves back and forth, GZ>Chi, Gz>screen

Chi: $\quad+G Z>A m$

$07 \mathrm{Am}: \quad$ [+Y You are the $\quad+(1.0)$

Am: tGz>Chi, LH moves in circle tGZ>Da +GZ>screen, LH down

Chi:

08 Am: the one who choose twho talks...tso=

Da $\quad+G Z>A m$

09 Da: $+=$ Oh I am the notetaker.=

Am: +GZ>SCreen--------+GZ>Chi +laughing

Chi: +RH lifts and touches her hair, GZ down 
$10 \mathrm{Am}:=+O h$ Ok, tlet's start. +(It's your) role thihih.

Excerpt 2 happened in Week 3 when Chi was the leader. Very similar to the situation in Excerpt 1, there was a period of lapse just before where the excerpt happened. Am was not the discussion leader, but she initiated the talk. In Line 01 she said, "let's move on, girls" without naming anyone specifically or gazing at anyone, so she did not explicitly select the next person to take a turn (Hauser, 2009). However, it was a complete turn and works as a TRP. Despite that, none of the participants was willing to take the next turn, resulting in a one-second pause in Line 02. During this time, Chi who was the discussion leader started pulling her laptop close to her body and retracted her arms while gazing at the screen, but she did not have a spoken response. Then, Am repeated her request in a more overt manner. This time, she lengthened the word "girls" and raised her intonation at the end of the word in Line 03. Still, nobody took a turn. Am waited for another one second then she selected Chi as the next speaker both verbally and nonverbally in Line 05. She also legitimized her nomination of Chi in lines 07-08. However, Am did not call out Chi's task-specific identity as the 'discussion leader' as Fa did to Yu in the previous excerpt. Instead, she had a one-second pause then said, "the one who choose, who talks." By doing this, she specified Chi's institutional obligation as the discussion leader, which was highly relevant to why she nominated Chi to take her turn, given at this point nobody had volunteered to talk. This had the same purpose as Fa's in the previous excerpt, which was to negotiate the primary speakership as well as orient the group members to their institutional responsibilities.

Throughout this sequence, Chi as the discussion leader had not produced any verbal communication. Instead, her body language showed her resistance to Am's request. Compared to Yu's situation, Chi responded in a very different way as the discussion leader.

The situation was resolved when Da nominated herself by saying that she's the notetaker in Line 09, in response to Am's request. While a notetaker's main responsibility is to take notes of the discussion, they are also expected to participate orally in the discussion. This claim of primary speakership aligns with Hauser's (2009) claim that "when a claim does lead to negotiation, the third part of the sequence is acceptance of the primary speakership by a different participant" (p.233).

This excerpt demonstrates how turn taking in a local context happens as the students fluidly manage their turn taking. Using each other's pre-existing obligations (i.e., the responsibilities of a discussion leader and a notetaker), they also orient themselves to a mutual institutional goal which is their engagement in the task. In Line 10, Am showed her readiness to move on as she successfully kept the discussion moving. 
Excerpt 3. Week 6

Fa: tGZ>screen. RH fingers move on touch pad. LH down

01 Fa: +Excuse me, I have another question. Who is notetaker?

Chi: +RH raises straight up

02 Chi: +I'm notetaker=

Fa: thH up, palm down, wiggle extended fingers of LH toward screen

MF moves on touch pad

03 Fa: =Oh.(.) +Did you wrote anything (.) there?

Chi + GZ>Fa, nodding

04 Chi: +Yeah, I wrote discussion questions.

Fa: $\quad+B H$ and arms retract to self, elbows on desk, GZ>screen

05 Fa: + (uh).

$06 \quad(3.5)$

Chi GZ>Fa, GZ>SCreen

Fa: $\quad+G Z>C h i, B H$ up, arm forward $+B H$ imitates typing action

07 Fa: +Notetaker I think should + write (.) what we're speaking about.

Chi tslides laptop to self, LH points to keyboard

08 Chi: +Yeah. I take note.=

Fa: $\quad$ +nodding

09 Fa: =+Uh uh. That's it.

Excerpt 3 happened in Week 6, which was the last round for this task. Chi and Fa were in different groups previously. In this round, Fa was the discussion leader and Chi was the notetaker. In this excerpt, the primary speakership was not the focus, however, through the organization of the talk, we can examine how the participants used their assigned roles to keep the orientation to the task. 
The excerpt starts with Fa asking the group who is the note-taker in Line 01. At this time, her eyes were gazing at the screen and her fingers were moving on the touchpad. Without any gap time, Chi answered $\mathrm{Fa}$ 's question and declared that she was the notetaker in Line 02. After saying an "oh" and a brief pause in Line 03, Fa asked Chi whether she had written down anything in the shared doc, both verbally and also non-verbally. She wiggled her left hand in front of the screen to explain that "here" meant the shared Google doc file. In Line 04, Chi answered Fa's questions. Chi said, "I wrote discussion questions," which was one of the responsibilities that she needed to do before the discussion session started. This was a complete turn and seems like a TRP. However, Fa only responded with a minimal response, which sounded like 'uh.' She also retracted her arms to herself, shifting her gaze to the screen. It looked like Chi's answer was not the answer that she was looking for, resulting in a long pause after that in Line 06. During this 3.5-second pause, Chi gazed at $\mathrm{Fa}$ and then gazed at the screen, but did not make any verbal expression, which seems like she probably also noticed something else was going on with Fa. After the long pause, Fa gazed at Chi and extended her arm and fingers as she said, "Notetaker I think should write what we're speaking about" in Line 07 . At the start of the word "write" she used her hands to imitate the typing action while at the start of 'we,' she moved her fingers with a circular movement. This body movement was much more elaborated when compared to Line 03, which showed that Fa wanted to make sure that Chi clearly understood what she was saying, as well as, emphasizing that Chi's other assigned responsibility was taking notes of the discussion session. This was very much in line with the situation in the previous two excerpts as the group members used the other participant's task-related identity to orient the task flow.

In Line 08, Chi confirmed that she was taking notes. Without any pause, Fa nodded her head and responded, "Uh-uh. That's it," which showed the satisfaction that her question was fully understood and that Chi was doing the institutional obligations that she was supposed to do.

Excerpt 3 is different from Excerpt 1 and 2 because the primary speaker Fa was also the discussion leader and she was performing her responsibility of making sure her group members were doing their pre-described duties. This process involved her strategically using Chi's role as the note-taker and orienting her to the institutional goal. As the note was being shared among the participants on Google Docs, taking notes is one way for the group participants to keep track of their task completion and a way for the teacher to later assess their task success. Therefore, making sure that this is being done properly is an important action that $\mathrm{Fa}$ did during this task-in-process.

In summary, in the course of examining the above excerpts through the lens of turn taking organization and the negotiation of primary speakers, the participants demonstrated numerous ways that they use each other's task-related identities to display their orientation to the institutional obligations. Their organization of turn taking was different from a mundane conversation in the sense that there was often a predetermined speakership in the group. It was also different from the task-as-workplan where the discussion leaders are responsible for allocating the turns during the discussion. For example, Excerpt 1 and 2 showed that when the discussions encountered a problem - in these cases an extensive pause with lapses - other members were ready to take responsibility and used the leader's assigned identity to orient them to their institutional obligation, which was to keep the discussion going and maintain participants' engagement in the discussions. In both cases, 
the discussion leaders constructed their identities very differently. In Excerpt 1, Yu takes up Fa's challenge of his discussion leader identity by verbally giving an account in response to Fa's complaint (i.e., the topic is difficult) as he mentioned political science is his major and that's why he picked that topic. He was also able to use a change-of-state token when suggesting that the group could discuss a different question. Meanwhile, Chi in Excerpt 2 did not attempt to react verbally to the challenge by her group member Am.

In both excerpts, while not being the group leaders, Fa and Am were able to skillfully negotiate the primary speakership by using the other group member's preassigned identities. These identities served the purpose of keeping the group-oriented to the institutional goal, which was the students' engagement in the task. This technique was also used by Fa again in Excerpt 3, where she explicitly checked on Chi's role as a notetaker and both verbally and non-verbally made sure that Chi understood her assigned responsibilities. All three of these excerpts are excellent demonstrations of how the turn taking organization is locally organized and constructed in the institutional context.

\section{Using Task Identities to Problematize the Situation}

The following two excerpts highlight another way that the participants used their task-related identities during their task interaction.

Excerpt 4. Week 2

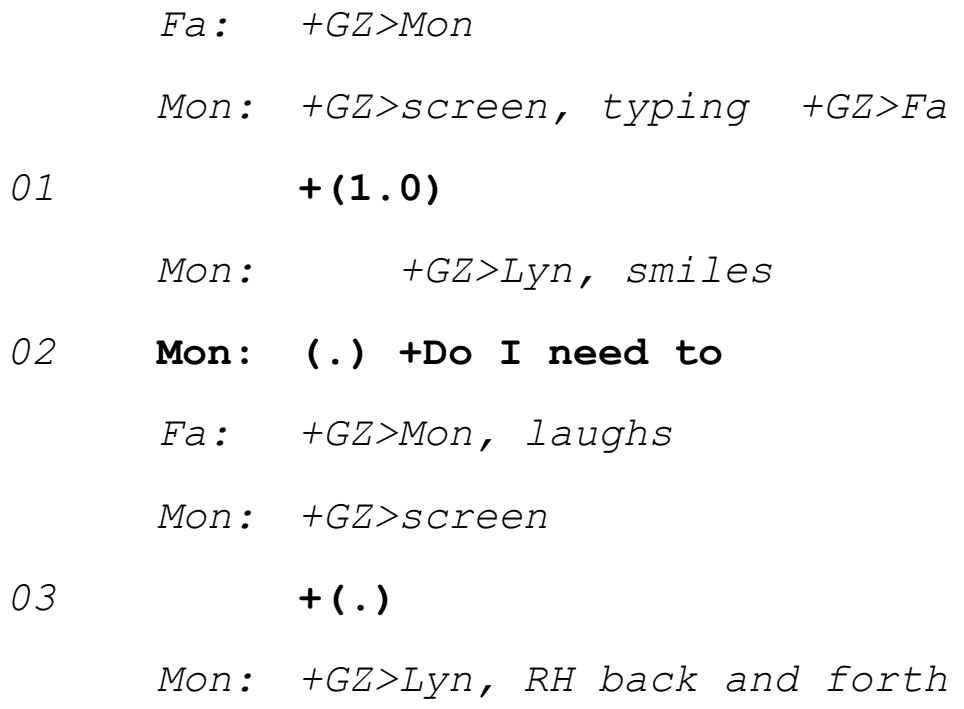




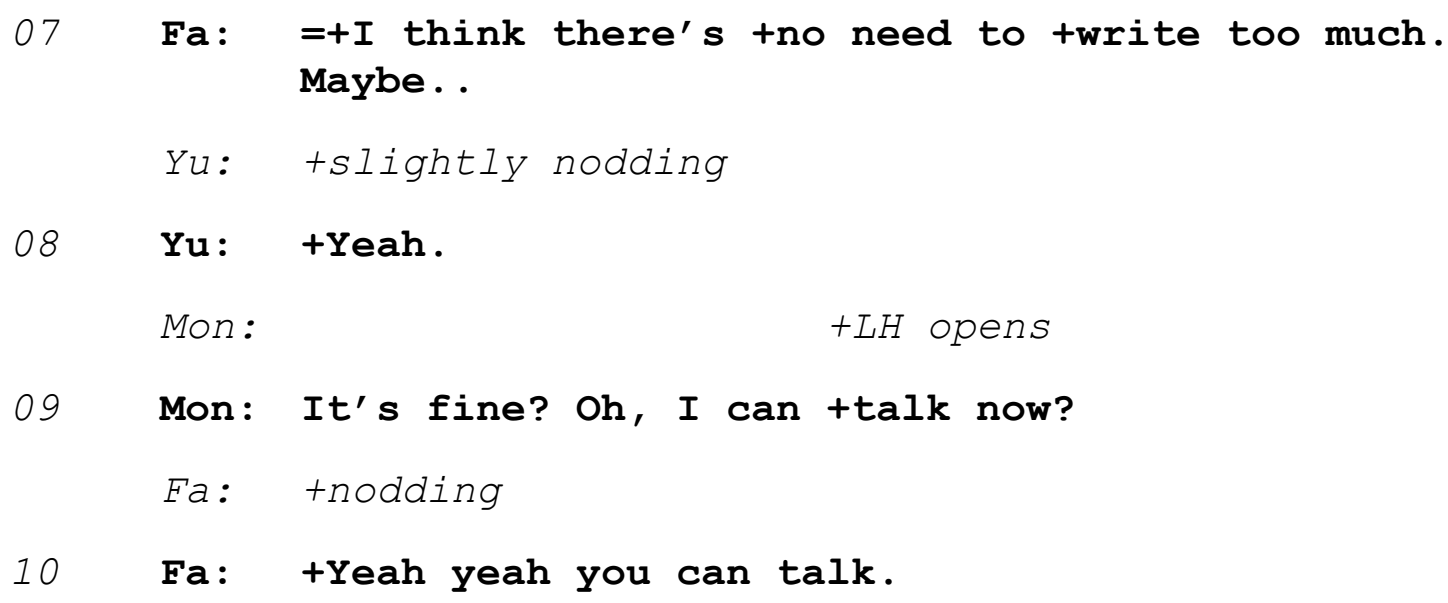

Excerpt 4 occurred in week 2 when Mon was the notetaker and Fa was the discussion leader. Fa selected Mon to take the turn nonverbally by gazing at her for one second in Line 01. Before the excerpt happened, the group took turns to discuss their discussion questions. However, Mon had not taken a turn yet, so Fa allocated the turn to her specifically. In response to Fa's nomination, from Line 02 to Line 05, Mon asked a question instead of taking the turn to discuss the question. She asked whether she needed to take notes on this question. Although she had been taking notes and understood that taking notes was part of her responsibilities, by asking again whether she needed to take notes on this task, Mon gave an account of why she had not taken her turn to discuss the questions. In a way, she was using her assigned identity as an excuse for not taking part in the discussion, or in other words, she problematized the situation.

In Line $07, \mathrm{Fa}$ answered Mon's question by saying that there was no need to write too much. Her statement received approval from Yu in Line 08. In Line 09, Mon asked a confirmation question, "it's fine?" and followed that with another question "Oh, I can talk now?" Using the word "can" here, she was emphasizing her confusion with the institutional responsibility that she needed to do in this situation. Through this, she again gave an account of why she did not participate in the task discussion before and problematized it through her other duty as notetaker. The strategy of using the task-related identity as a resource to explain the problems that arose during the discussion appears again in Excerpt 5.

Excerpt 5. Week 6

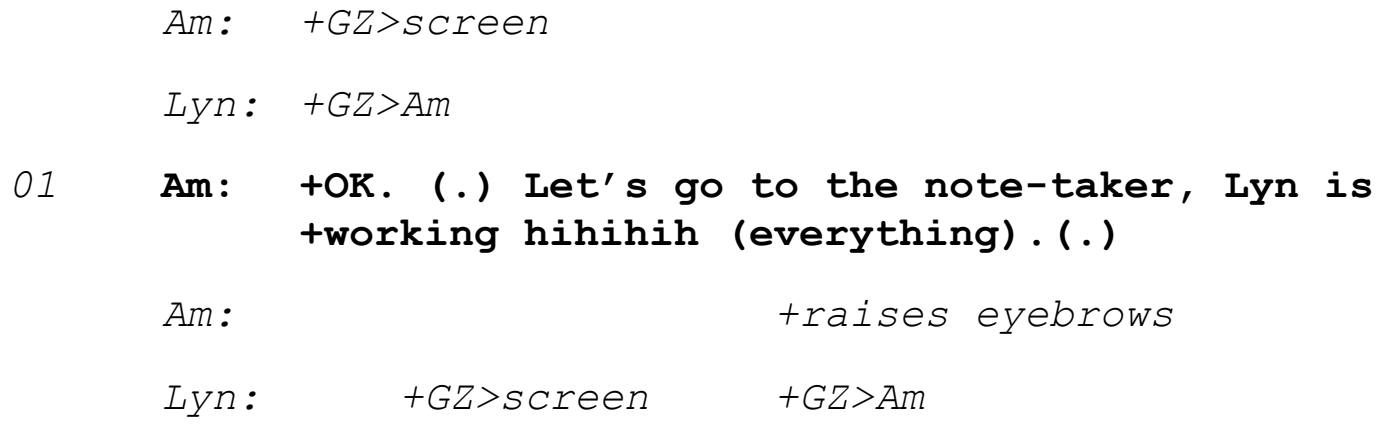


02 Am: OK, tso luminary. toh no? (.)

Am: tGZ>Lyn, RH pointing finger >Lyn +GZ>Da, $\mathrm{RH}$ down

$\mathrm{Da}: \quad+\mathrm{GZ}>\mathrm{Am}$

03 Am: Hou should provide the questions as well, tright?

Da: $\quad$ nod head, GZ>Linda

$05+(1.0)$

$A m: \quad+G Z>\operatorname{Lyn}$

Lyn: tsmiles, LH covers mouth thead shakes, RH taps the desk, LH opens up, touches ears

06 Lyn: $+I$ don't know. Like I don' $t+($.$) do that in my old$ group.

07 Lyn: I just take note and [

Am: $\quad+$ GZ>screen $\quad+R H$ takes off glasses

08 Am: [There is also another question, like +discussing questions and

$A m: \quad \quad+G Z>D a$ + GZ>Screen

09 Am: also twhat were other the questions, tcontextualizer questions? Or what is..

Am: tshakes head $\quad+R H$ pointing finger raises up

$10 \mathrm{Am}$ : tno no not contextualizer.tJust wait.

$A m: \quad+b o d y$ straightens up, RH points to screen

11 Am: +Comprehension questions.

Da: thods head

12 Da: tUhm.

Am: thods head tGZ>Lyn thods head

13 Am: +It's the +notetaker's. =+I checked it.

Lyn: $\quad+$ Gz>screen 
14 Lyn: OK +(I see) $=$

$\begin{array}{rr}\text { Am: } & \text { tGZ>screen, } R H \text { up and down } \\ \text { Lyn: } & +G Z>A m \quad+G Z>\text { down }\end{array}$

15 Am: =+yeah, tok. tWe we can make those questions.

This excerpt occurred in week 6 after the students had formed a new group and it was also the last week of the Reading Circle task. Am and Lyn were in different groups previously. This time Am was the discussion leader of the group. She was in charge of the discussion and allocated the turn to Lyn in Line 01. She also called out Lyn's role as the notetaker. However, Lyn did not take this turn. So, for a second, Am questioned if it's the luminary that she should allocate the turn to in Line 02. Prior to this excerpt, the group talked about the discussion questions. And now they were about to start the comprehension questions, which the note-taker was supposed to have prepared. We can see Am's slight confusion in Line 02 but, quickly after that in Line 03, she was sure that it was the notetaker who should take the turn. This time, she nominated Lyn not just verbally by saying "You should provide the questions" but also nonverbally as she gazed at Lyn while pointing a finger at Lyn using her right hand. At the end of Line 03, she also looked for an agreement from another group member, Da, by saying "right?" while gazing at Da. Da then showed her approval by nonverbally nodding her head in Line 05.

After a one-second pause, Lyn gave her account for not having the comprehension questions in Line 06. She said that she did not know, and it was because she did not do that in her previous group. She also elaborated that in Line 07 by saying that she only took notes in her old group. By referring to her responsibilities in the old group, she problematized the task. It was what she did in the previous group, and it was not that she misunderstood the task responsibilities.

From Line 09-13, Am convinced Lyn that it was the notetaker's role to be responsible for the comprehension questions. In Line 13, she had a double statement by saying 'it's the notetaker's (job) and "I checked it" while gazing at Lyn. However, Lyn only said, "OK, I see" in Line 14. In Line 15, however, Am decided to work on the questions as the whole team.

In both Excerpt 4 and Excerpt 5, Mon and Lyn used their context-specific identities in a different way than what the learners did in Excerpt 1, 2 and 3. Here, they both used their own assigned roles as accounts for the problems during the task interaction. While 1, 2 and 3 have demonstrated that the participants successfully used each other's task-related identities to help keep the task group-oriented, Excerpts 4 and 5, in contrast, show how the participants used those assigned obligations as resources to problematize their participation in the groups. In Excerpt 4, Lyn used her task-related responsibilities in her previous discussion group as an account for not distributing the comprehension questions to the new group. Meanwhile, in Excerpt 5, Mon used one of the assigned obligations of a notetaker, which is to keep notes of the group discussion, as an account for her not taking the role of a primary speaker when it was her turn. 


\section{Discussion and Implications for Task Design}

Task-interaction is considered institutional interaction because the participants use the target language in a typical way that is motivated by the task-specific context (Hauser, 2013). Each institutional interaction often reveals unique sets of turns or a "fingerprint" (Heritage \& Clayman, 2010, p. 10). For example, if the talk-in-action happens in a discussion session that has a leader, the set of turns will include certain types of questions or turns initiated by the leader. In the data analyzed above, however, we have seen a different pattern. For example, in Excerpts 1 and 2, the group members who were not the leaders used the assigned identities of the leaders to negotiate the primary speakership and oriented the group to the task. In Excerpt 3, on the other hand, the discussion leader was the one who used their group member's pre-described responsibility to manage the institutional goals. This is aligned with previous research on task-in-process (Samuda, 2015) as it revealed that as the students participated in the task-interaction, the assigned roles of each member became blurry and the task departed from the teacher's original plan (e.g., Hellermann \& Pekarek Doehler, 2010). Data in the study have also shown how the participants' task-related identities were used in various ways, whether for effective task management purposes or for problematizing the task. This study, therefore, started filling in the gap in CA research in this domain of TBLT as it expanded the discussion of task interaction into the role of participants' task-related identities, specifically in the context of a reading circle task.

In addition, the analysis also showed that the group members used a variety of strategies to negotiate the primary speakership. They include (a) making a complaint (Excerpt 1), (b) using other's assigned identity to orient them to their responsibility of a primary speakership (Excerpt 1, with laughing, teasing; Excerpt 2), (c) moving from a general call (i.e., "girls") to a specific person (Excerpt 2); and (d) selecting the primary speaker directly (Excerpt 4). These choices of strategies are not global rules that determine how the participants should handle the transitioning of primary speakership, but instead, it is through the collaboration and task interaction in a local context that makes the patterns of the strategies emerge as "concrete" and "observable" (Hauser, 2009, p. 238).

Another noteworthy point is that four out of the five excerpts examined above concern the participants' interaction management, rather than the topics of these discussions. While the task content is certainly important, it is apparent that task management is crucial, as well, to promote optimal learning. As the issues with task management arose multiple times and even during the last round of the Reading Circle task, it hints at possible institutional problems, i.e., the task design and implementation process.

According to Robinson's (2011) task complexity model, this reading circle task is considered a complex task since it involves a variety of elements that contributes to the complexity of the task. Some of those elements include the task condition as the fairly large number of participants (four members per group); task complexity such as short planning time (the leaders read the summary of the article and then the group are supposed to discuss the questions immediately); and a large number of steps that the participants need to do (e.g., post the articles, prepare different types of questions, give opinions during the discussions, take notes, etc.). In addition, depending on the article that the group 
members prepare, prior topic knowledge may also be required (such as the topic about the U.S. midterm elections).

In all the excerpts above, as well as the data that were not presented here due to space limitations, the most problematic roles in this task were of the discussion leader and the notetaker. The discussion leader needed the skills of leadership such as efficiency to distribute the turns in the group (e.g., in Excerpt 2), create discussion questions, and the skills to modify the focus to meet the institutional goal (i.e., keep the discussion flow) (e.g., in Excerpt 1). Notetakers need to be able to create comprehension questions before the discussion circle, as well as multitasking during the discussion circles in order to both take efficient notes and take the responsibility of being a primary speaker during their turn. While all of these tasks are important and relevant to college students since they are realworld needs, the analysis has shown that it can be problematic because of the complexity those two roles caused for the students' interactions. As they spend an extensive amount of time in their group figuring out those interactional management issues, it could inhibit their opportunities for learning. One way to simplify the task is to create a group of only three students and reduce the responsibilities of the group members. Another way to enhance the quality of the task is to have a model group and explicitly check the participants' understanding of their assigned roles before the first round of the Reading Circle starts. With those extra steps, the task can be more fruitful for the participants.

Furthermore, among the excerpts examined in this study, Fa and Am are the most active members in the group that they were in. They constantly checked on other participants' roles, initiated the turns, and oriented the group to the task-whether they were the leader of that circle or not. While Fa was the only graduate student (academically more advanced and also older than the rest of the group members), Am was a freshman in Business. Therefore, this group's dynamics were probably not only influenced by the differences in age and experience. Many other issues can affect the group dynamics such as individual differences, willingness to talk, task motivation, etc. Therefore, understanding the dynamics of the group is extremely important for task designers to make the task work well. Teachers can do this through observations and adjusting the members of the group, as needed. By observing and tracing the sequential organizations of task interaction (Lee \& Hellermann, 2014, Ro, 2018), teachers could get important insights on various ways to strategically improve the task.

Finally, when the teacher designed this task, one of the task outcomes was for the participants to take turns leading a discussion efficiently, and other members to participate in the discussion in an appropriate way. The leaders need to raise good discussion questions and initiate the turns so that it brings in good discussion among all the members. The participants need to orient well to the rules of turn taking during task-interaction so that they can prove their understanding of the questions, express their arguments or opinions clearly as well as pragmatically taking part in the group discussion. Although these goals are very relevant to the learner's real-world needs, assessment of their completeness can be challenging to accomplish. While the recommendations of how to assess task completeness are beyond the scope of this paper, knowing the specific outcomes of the task would likely increase the learners' motivation in completing the task and staying focused to achieve these outcomes. One possible way to do this is to make these goals more visible and emphasized during the pre-task session. The learners could also do self-reflection during the post-task phase where they reflect on their learning 
process and assess their level of task completeness. By making the changes, the reading circle itself can also be improved as a task by Ellis' (2009) definition.

\section{Conclusion}

This study has looked at the task-related identities that the participants exposed and how they exploit them as they manage their task orientation. Through detailed analysis of the talk-in-action during the task-in-process phase, this research contributes to the body of research in task interaction by presenting a different set of turns that the participants use to manage the task: whether to orient everyone to the task efficiently or to problematize the task through contributing to their task-specific identities. The CA method has also given the researcher an epistemic lens to discover the institutionality of task interaction and participants' orientation to the mutual goals. The interaction also shows that the learners were able to use their assigned identities skillfully to orient the group to the task. Since this phenomenon happened in this Reading Circle task, future research can look at different tasks and see whether the structure of the tasks affects how the participants use their taskrelated identities in various ways to the orientation of the task. Finally, while the intended goals were good, the task demonstrates several drawbacks that needed adjustment to make it more efficient and support the students' learning. The study hopes to bring useful insights to TBLT teachers who intend to use the reading circle task or similar role-play discussion task in a reading class.

Correspondence should be addressed to Hoa Le.

Email: hoavinhle@gmail.com

\section{References}

Arminen, I. (2005). Institutional interaction: Studies of talk at work. Aldershot.

Balaman, U., \& Sert, O. (2017a). Local contingencies in L2 tasks: A comparison of context-sensitive interactional achievements across two different task types. Bellaterra Journal of Teaching \& Learning Language \& Literature, 10(3), 9-27. https://doi.org/10.5565/rev/jtl3.746

Balaman, U., \& Sert, O. (2017b). The coordination of online L2 interaction and orientations to task interface for epistemic progression. Journal of Pragmatics, 115, 115-129. https://doi.org/10.1016/j.pragma.2017.01.015

Breen, M. (1987/2009). Learner contributions to task design. In K. Van den Branden, M. Bygate, \& J. M. Norris (Eds.), Task-based language teaching: A reader (pp. 333356). John Benjamins Publishing Company.

Burch, A. R. (2014). Pursuing information: A conversation analytic perspective on communication strategies. Language Learning, 64, 651-684

Daniels, H. (2002). Literature circles: Voice and choice in book clubs and reading groups ( $2^{\text {nd }}$ ed.). Pembroke.

Drew, P., \& Heritage, J. (Eds.) (1992). Talk at work: Interaction in institutional settings. Cambridge University Press.

Ellis, R. (2003). Task-based language learning and teaching. Oxford University Press.

Ellis, R. (2005). Preface. In R. Ellis (Ed.), Planning and task performance in a second language (pp. vii-viii). Amsterdam: John Benjamins. 
Ellis, R. (2009). Task-based language teaching: Sorting out the misunderstandings. International Journal of Applied Linguistics, 19(3), 221-246.

Furr, M. (2004). Literature circles for the EFL classroom. Available at http://resourcesforteflteachers.pbworks.com/f/Literature+Circles+for+EFL+Students .pdf (accessed on 5 January 2021).

Gardner, R. (2019). Classroom interaction research: The state of the art, Research on Language and Social Interaction, 52(3), 212-226, http://doi.org/10.1080/08351813.2019.1631037

Hauser, E. (2009). Turn-taking and primary speakership during a student discussion. In H. thi Nguyen \& G. Kasper (Eds.), Talk-in-interaction: Multilingual perspectives (pp. 215-244). National Foreign Language Resource Center.

Hauser, E. (2013). Beyond intersubjectivity: Task orientation and first language use in foreign language discussions. Pragmatics and Society, 4, 285-316.

Hellermann, J., \& Cole, E. (2009). Practices for social interaction in the language learning classroom: Disengagements from dyadic task interaction. Applied Linguistics, 30(2), $186-215$.

Hellermann, J., \& Pekarek Doehler, S. (2010). On the contingent nature of languagelearning tasks. Classroom Discourse, 1, 25-45.

Heritage, J., \& Clayman, S. (2010). Talk in action: Interactions, identities, and institutions. John Wiley \& Sons. https://doi.org/10.1002/9781444318135

Huth, T. (2011). Conversation analysis and language classroom discourse. Language and Linguistics Compass, 5, 297-309. http://doi.org/10.1111/j.1749-818X.2011.00277.x

Kasper, G. (2004). Participation orientations in German conversation-for-learning. The Modern Language Journal, 88(4), 551-576. https://doi.org/10.1111/j.0026-7902.2004.t01-18-.x

Lee, Y. A., \& Hellermann, J. (2014). Tracing developmental changes through conversation analysis: Cross-sectional and longitudinal analysis. TESOL Quarterly, 48(4), 763788.

Long, M. H. (1985). A role for instruction in second language acquisition: Task based language teaching. In Hyltenstam, K., \& Pienemann, M. (Eds.), Modeling and assessing second language development (pp. 77-99). Multilingual Matters.

Long, M. (2015). Second language acquisition and task-based language teaching. WileyBlackwell.

Markee, N. (2000). Conversation analysis. Lawrence Erlbaum Associates. https://doi.org/10.4324/9781410606471

Markee, N., \& Kunitz, S. (2013). Doing planning and task performance in second language acquisition: An ethnomethodological respecification. Language Learning, 63(4), $629-664$.

Mori, J. (2002). Task design, plan, and development of talk-in-interaction: An analysis of a small group activity in a Japanese language classroom. Applied Linguistics, 23(3), $323-347$.

Jenks, C. J. (2007). Floor management in task-based interaction: The interactional role of participatory structures. System, 35(4), 609-622.

Jenks, C. J. (2009). Exchanging missing information in tasks: Old and new interpretations. The Modern Language Journal, 93(2), 185-194. 
Jefferson, G. (2004). Glossary of transcript symbols with an introduction. In G. Lerner (Ed.), Conversation analysis: Studies from the first generation (pp. 13-31). John Benjamins.

Ro, E. (2018). Facilitating an L2 book club: A conversation analytic study of task management. Modern Language Journal, 102(1), 181-198. http://doi.org/10.1111/modl.12450.

Robinson, P. (2011). Second language task complexity: Researching the Cognition Hypothesis of language learning and performance. John Benjamins.

Samuda, V. (2015). Tasks, design, and the architecture of pedagogical spaces. In M. Bygate (Ed.), Domains and directions in the development of TBLT (pp. 271-302). John Benjamins.

Sacks, H., Schegloff, E. A., \& Jefferson, G. (1974). A simplest systematic for the organization for turn taking for conversation. Language, 50, 693-735.

Sacks, H., Schegloff, E. A., \& Jefferson, G. (1978). A simplest systematics for the organization of turn taking for conversation. In J. Schenkein (Ed.), Studies in the organization of conversational interaction (pp. 7-57). Academic Press.

Schegloff, E. A. (2000). Overlapping talk and the organization of turn-taking for conversation. Language in Society, 29, 1-63.

Schegloff, E. A. (2007). Sequence organization in interaction: A primer in conversation analysis, Volume 1. Cambridge University Press.

Seburn, T. (2015). Academic reading circles. Toronto, Canada: The Round.

Seedhouse, P. (1996). Classroom interaction: Possibilities and impossibilities. ELT Journal, 50(1), 16-24. http://doi/10.1093/elt/50.1.16

Seedhouse, P. (1999). Task-based interaction. ELT Journal, 53(3), 149-156.

Seedhouse, P. (2004). The interactional architecture of the language classroom: A conversation analysis perspective. Wiley-Blackwell.

Seedhouse, P. (2005). Conversation analysis and language learning. Language Teaching, 38(4), 165-187. https://doi.org/10.1017/S0261444805003010

Seedhouse, P. (2009). The interactional architecture of the language classroom. Bellaterra Journal of Teaching \& Learning Language \& Literature, 1(1), 1-13. http://doi.org/ $10.5565 / \mathrm{rev} / \mathrm{jt} 13.32$.

Shelton-Strong, S. J. (2012). Literature circles in ELT. ELT Journal, 66(2), 214-223.

Skehan, P. (1998). A cognitive approach to language learning. Oxford Applied Linguistics. 


\section{Appendix \\ Transcription Conventions}

Conventions for the Description of Talk (adapted from Jefferson, 2004)

[

$(0.2)$

(.)

wo:rd

word.

word,

word?

word

@@
Overlap

Latching

Timed silence within or between utterances in tenths of seconds

Micro-pause, shorter than 0.2 seconds

Extension of the sound

Falling intonation, e.g., final intonation

Continuing intonation

Rising intonation

Stressed syllable

Laughing voice

Conventions for the Description of Embodied Action (adapted from Burch, 2014)

$\mathrm{H}$

F

$\mathrm{R}$

$\mathrm{L}$

MF

$\mathrm{B}$

GZ

$+$

$--$

italics

$\uparrow \downarrow$
Hand(s)

Finger

Right

Left

Middle finger

Both

gaze (starting at the point of the time)

Place where action begins in relation to talk

Holding gesture or gaze in place

Embodiments

Up and down movement 